\title{
Mechanisms of the "Low-Flow" State during Resuscitation of the Totally Ischemic Brain
}

\author{
W. A. TWEED, J. G. WADE AND W J. DAVIDSON
}

SUMMARY. Resuscitation of the brain following total circulatory arrest may be impeded by difficulty in establishing cerebral tissue perfusion, a postischemic "low-flow" state. We have confirmed this hypothesis in a rat model of total cerebral ischemia and have demonstrated marked improvement in post-ischemic brain tissue perfusion following epinephrine injection. This is mainly due to the systemic vascular effects of epinephrine, resulting in improved central aortic pressure and cerebral perfusion pressure. Hyperkalemic

RÉSUMÉ: La réactivation $d u$ cerveau après un arrêt cardiaque complet peut être entravée par la difficulté d'établir la perfusion du tissu cérébral, un état de lenteur du flot post-ischémique. Nous avons confirmé cette hypothèse dans un modèle d'ischémie cérébrale totale chez le rat et avons démontré une amélioration marquée dans la perfusion post-ischémique du tissu cérébral après une injection d'épinéphrine. Ceci est principalement dû aux effets vasculaires systémiques de l'épinéphrine, résultant en une amélioration de la pression aortique centrale et de la pression de la perfusion cérébrale. Une vasoconstric- induced vasoconstriction has also been postulated as a cause of the "low-flow". We have, therefore, investigated the in vitro effects of increasing potassium ion concentration on cerebrovascular smooth muscle strips. Large arteries constrict, while small arteries dilate in response to hyperkalemia. The net effect on cerebral blood flow remains unsettled. Our research to date suggests that resuscitation of the totally ischemic brain, in animal models at least, is enhanced by epinephrine, mainly via its effects on central aortic pressure.

tion induite par l'hyperkaliémie a également été postulée comme cause possible de ce flot lent. Nous avons donc investigué les effets in vitro de l'augmentation de la concentration de l'ion potassium sur des bandes de muscles lisses de la vasculature cérébrale. Les grandes artères rétrécissent, pendant que les petites artères se dilatent en réponse à l'hyperkaliémie. L'effet sur le débit sanguin cérébral demeure incertain. Notre recherche à date suggère que la réactivation $d u$ cerveau totalement ischémique, du moins dans certains modèles animaux, est augmentée par l'épinéphrine, principalement via ses effets sur la pression aortique centrale.
From the Departments of Anesthesia and Pharmacology \& Therapeutics Faculty of Medicine, University of Manitoba

Reprint requests to Dr. W. A. Tweed, Department of Anesthesia, University of Manitoba, Health Sciences Centre - General, 700 William Ave., Winnipeg, Canada. R3E 0Z3.
Previous studies in the rat have demonstrated both a marked reduction in cerebral perfusion rate following total cerebral ischemia of 8 and 16 minutes (Wade et al., 1975), and partial reversal of this "lowflow" state by epinephrine (Wade et al., 1976). The post ischemia "lowflow" or "no-reflow" state has also been observed by other investigators, generally in small animal preparations (Ames et al., 1968; Olsson and Hossmann, 1970; Osburne and Halsey, 1975). Several mechanisms have been proposed to explain this observation.

1) Mechanical obstruction of the cerebral microvasculature by glial and endothelial cell swelling (edema) or intravascular obstruction by erythrocyte aggregation was proposed by Ames et al., (1968).

2) Wade et al., (1975) have postulated an increase in cerebrovascular resistance caused by vasoconstriction. In those studies prolonged cerebral ischemia was accompanied by a marked increase in $\mathrm{K}^{+}$concentration in the cisternal CSF (19.4 $\mathrm{mEq} / 1$ after 16 minutes of ischemia). Using potassium sensitive electrodes in the cortical areas a marked increase in extracellular potassium (16-100 $\mathrm{mEq} / 1)$ was observed by Morris (1974) immediately following cerebral anoxia. Although many vasoactive substances might be liberated during ischemia, we have speculated that the large rise in interstitial potassium concentration following prolonged total cerebral ischemia might, by depolarizing vascular smooth muscle cells, cause marked vasoconstriction and an increase in cerebrovascular resistance.

3) A reduction in cerebral perfusion pressure during attempted re- 
circulation of the brain might explain the "low-flow" state. Cerebral perfusion pressure depends on intracranial pressure and central arterial blood pressure. Intracranial pressure rises only slightly following ischemia (Yashon et al., 1971; Wade et al., 1975), but independent measurements of central arterial pressure in the animal models during attempted perfusion have not been made.

The present studies were designed to:

1) Confirm the "low-flow" state following prolonged total cerebral ischemia using a different method for measuring cerebral perfusion rate (Xe $\mathrm{Xe}^{133}$ washout method).

2) To further examine the effect of epinephrine on the "low-flow" state.

3) To examine possible mechanisms of the "low-flow" state, by a) estimating cerebral perfusion pressure during attempts at re-perfusion of the rat brain by independently measuring aortic arch pressure with a second cathetertransducer system, and b) examining the effect of $\mathrm{K}^{+}$on cerebral arterial smooth muscle in vitro.

\section{METHODS}

\section{In vivo Studies}

Sprague-Dawley rats weighing approximately 400 grams were anesthetized with halothane $/ \mathrm{O}_{2}$. After tracheostomy anesthesia was maintained with $70 \% \mathrm{~N}_{2} \mathrm{O}$ in oxygen and gallamine $40 \mathrm{mg} / \mathrm{kg}$. Ventilation was controlled to maintain $\mathrm{PaCO}_{2}$ between 35 and 40 torr. Rectal temperature was kept at $37.5 \pm 0.5^{\circ} \mathrm{C}$ by a heating pad. Mean aortic pressure was greater than 120 torr. A polyethylene catheter was advanced from the abdominal into the thoracic aorta. The thorax was opened broadly by cutting the ribs on both sides of the sternum allowing free exposure of the heart and major vessels. Silk threads were placed around the ascending aorta close to the heart and $500 \mathrm{mg}$ heparin injected. Circulation was arrested by tying off the aortic root, while the completeness of occlusion was checked by monitoring aortic pressure.
The cerebral perfusion rate was determined by measuring the washout from the brain of Xenon ${ }^{133}$ by a perfusion fluid of $4 \%$ albumin in saline solution, adjusted to a $\mathrm{pH}$ of 7.40 and warmed to $37^{\circ} \mathrm{C}$. The extracranial tissues were stripped from the skull and a collimated scintillation detector was placed directly against the skull in the region of the cerebral hemispheres. After occluding the descending aorta, the brain was loaded with $1 \mathrm{mCi}$ of Xenon ${ }^{\mathbf{1 3 3}}$ injected through the aortic catheter and flushed in with $1 \mathrm{ml}$ saline and $0.75 \mathrm{ml}$ of the animal's own blood. A plateau of counts was obtained confirming complete cerebral ischemia. After the desired ischemic period, the brain was perfused with the albumin/saline solution through the aortic catheter with a perfusion pressure of 150 torr applied to the bag of perfusion solution. Perfusion was begun approximately $1 \mathrm{~min}$ after aortic occlusion in 16 rats (control) and after 16 min of occlusion in 10 rats. In 6 rats, in which no washout of Xenon was observed on attempting perfusion after $16 \mathrm{~min}$ of ischemia, $1 \mathrm{ml}$ of 1:20,000 epinephrine in saline was injected at 150 torr and perfusion was continued.

The cerebral perfusion rate was calculated from the Xenon ${ }^{133}$ washout curve by measuring the logarithmic decay rate $(k)$ of the initial part of the washout curve. ( $\mathrm{k}$ is the slope in fractions of decade per minute of the initial portion of the logarithmically recorded washout curve and is directly proportional to cerebral blood flow).

In 6 additional rats a second catheter was inserted into a brachiocephalic artery to independently measure aortic arch pressure. Aortic pressure during artificial perfusion (at 150 torr) was measured after 1 and $16 \mathrm{~min}$ of ischemia and after 16 min of ischemia plus epinephrine.

\section{In-vitro Studies}

Bovine brains were obtained immediately after slaughter from a local abattoir. The entire brain was rinsed and placed in iced $\left(4^{\circ} \mathrm{C}\right)$ Krebs-Henseleit solution, equilibrated with $95 \% \mathrm{O}_{2}$ and $5 \% \mathrm{CO}_{2}$, for transport to the laboratory.
Helical strips, approximately 20 $\mathrm{mm}$ long and $1.5 \mathrm{~mm}$ wide, were cut from cerebral arteries of different diameters down to about $0.3 \mathrm{~mm}$ diameter. The strips were suspended horizontally in a $10 \mathrm{ml}$ plexiglass bath containing Krebs-Henseleit solution at $37^{\circ} \mathrm{C}$, bubbled with $95 \%$ $\mathrm{O}_{2}$ and $5 \% \mathrm{CO}_{2}$. Bathing fluid can be changed by a drainage or overflow procedure. One end of the muscle strip was fixed, the other end connected to a sensitive force displacement transducer (Statham P-16). Strips were allowed to equilibrate for 1 hour during which the bathing fluid was changed every 10 minutes.

A resting tension of 1 gram was applied and isometric tension developed by the muscle strip during control and experimental conditions was monitored on a Hewlett Packard 141B storage oscilloscope and stored in a Hewlett Packard No. 3960 tape recorder. Measurement of tension changes were made from projected photographic recordings. Experimental conditions were changed by changing the composition of the bath.

Mechanical responses of cerebral arteries of different diameters to increasing $\mathrm{K}^{+}$concentration in the bath were measured.

\section{In vivo Studies}

Cerebral perfusion rates (CPR) are expressed as percent of control (Figure 1). Following 16 minutes of total cerebral ischemia CPR was reduced to $8.3 \%$ of control, but with epinephrine injection, rose to $40.8 \%$ of control. At a perfusion pressure of 150 torr applied to the bag at the proximal end of the perfusion catheter, mean aortic arch pressure was 90 torr in control rats. After $16 \mathrm{mi}$ nutes of total ischemia under the same perfusion conditions aortic arch pressure was reduced to 45 torr, and was elevated after epinephrine injection to 95 torr (Figure 2). The change is undoubtedly due to the fixed resistance of the perfusion catheter, limiting inflow of perfusion solution, and a decreased peripheral vascular resistance in the ischemic rat. Epinephrine in this situation ex- 


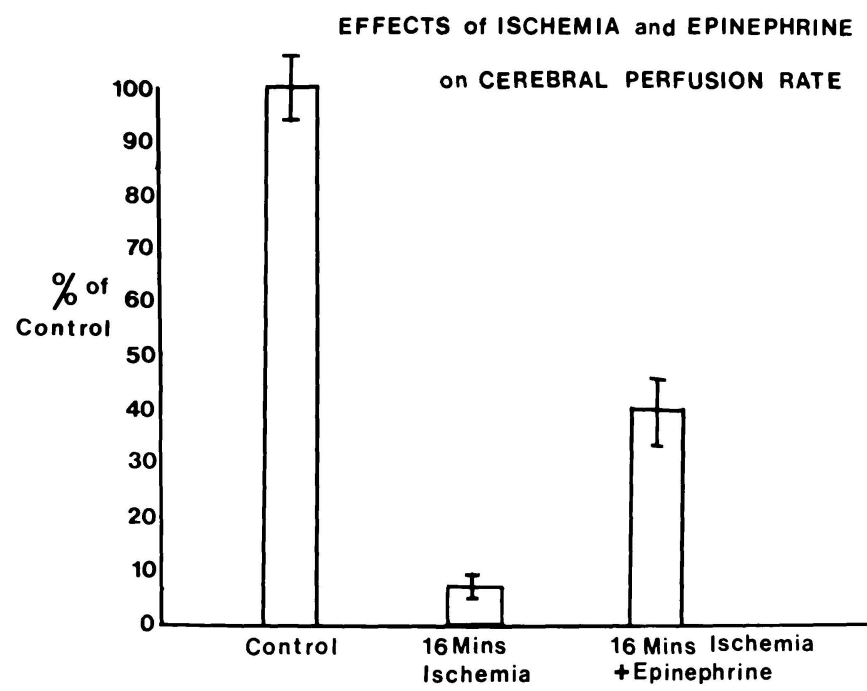

Figure 1 -Cerebral perfusion rate on the vertical axis, is expressed at percent of control (control $=100 \%)$. Cerebral perfusion rate immediately following 16 minutes of total ischemia was reduced to less than $10 \%$ of control, but with epinephrine injection after 16 minutes of ischemia it increased to $40 \%$ of control.

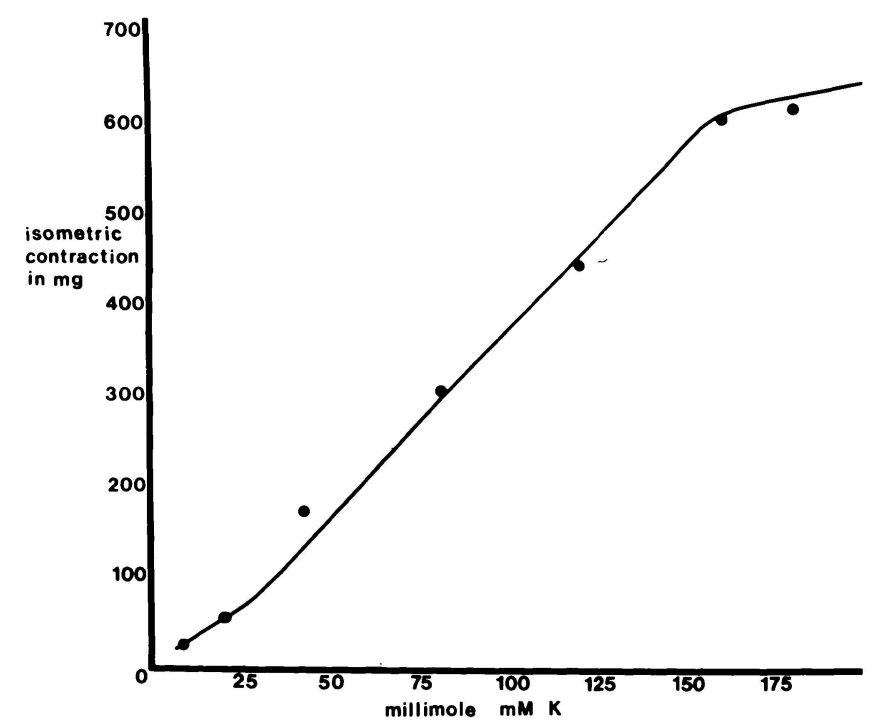

Figure 3-Contractile dose-response curve of a cerebral arterial smooth muscle strip from a "large" artery in response to increasing $\mathrm{K}^{+}$concentration in the bath.

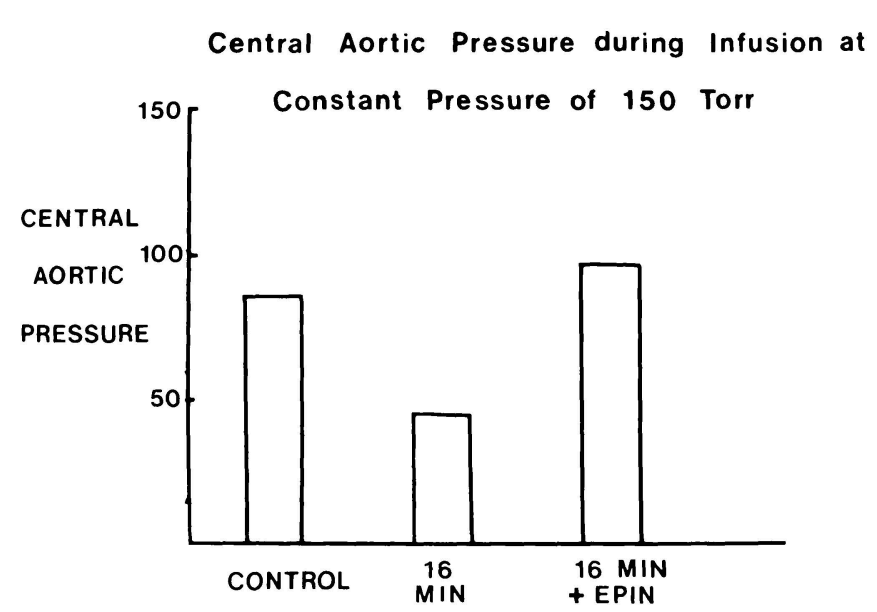

Figure 2-Central aortic pressure was independently measured by a second catheter introduced into the arch of the aorta. During control perfusion, when a constant pressure of 150 torr was applied to the bag of perfusion solution, central aortic pressure was 90 torr. Following 16 minutes of ischemia it was only 45 torr but increased after epinephrine injection to 95 torr.

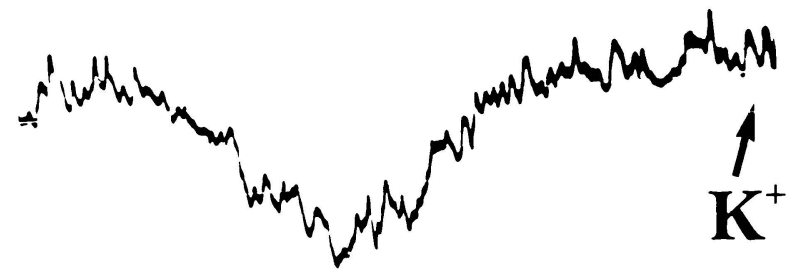

Figure 4-Dilator response of a cerebral arterial smooth muscle strip from a "small" artery in response to potassium (100 $\mathrm{Meq} / 1)$. The time scale is from right to left. erts a marked systemic vasoconstrictor effect.

\section{In vitro Studies}

The following results were obtained with in vitro preparations of bovine cerebral arteries. Two different populations of cerebral arteries could be identified: (1) arteries 0.7 $2 \mathrm{~mm}$ in diameter normally showed no spontaneous mechanical activity and contracted in a dose related manner to increasing $\mathrm{K}^{+}$concentration (Figure 3); (2) arteries $0.3-0.5$ $\mathrm{mm}$ in diameter normally showed intensive spontaneous mechanical activity and relaxed in response to increasing $\mathrm{K}^{+}$concentration (Figure 4).

\section{DISCUSSION}

Despite considerable research the mechanisms of anoxic-ischemic brain injury remain unresolved. However, a number of experimental studies suggest that portions of the brain may remain ischemic during attempted resuscitation from total circulatory arrests (Ames et al., 
1968; Ginsberg and Myers, 1972; Fischer, 1973; Osburne and Halsey, 1975; Wade et al., 1975; Little et al., 1976). This has led to the hypothesis that recovery of cerebral function may depend, at least in part, on the restoration of local circulation. Although the experimental observation of "low-flow" or "no reflow" following total cerebral ischemia has been well documented, these experiments have generally been done in small animals, with artificial perfusion, and without measurement of cerebral perfusion pressure. Whether this "low-flow" state represents an experimental artifact, or is a real clinical entity has not been clarified. Although the mechanisms and clinical significance remain in doubt, there is experimental evidence in animals that the postischemic "low-flow" state is associated with poor neurologic recovery but is at least partially reversible.

When cats (Hossman and Lechtape-Grüter, 1971) and gerbils (Osburne and Halsey, 1975) were subjected to prolonged ischemia, only those animals with postischemic hyperemia recovered EEG activity. Both cerebral hyperemia and EEG recovery in the cat correlated with recovery of systemic blood pressure (Hossmann and Hossman, 1973).

In rabbits, pharmacologic support of systemic blood pressure after ischemia was associated with neurological recovery (Cantu et al., 1969), while those rabbits with no recovery exhibited severe hypotension. Safar et al., (1976) were able to enhance neurological recovery in dogs by therapy designed to improve microvascular blood flow: pharmacologic support of blood pressure, heparinization and hemodilution with Dextran-40. Thus, experimental evidence from animal models strongly indicates that better neurologic recovery is observed in animals with adequate systemic and cerebral circulation in the immediate post-ischemic period.

Pioneer workers (Ames et al., 1968; Chiang et al, 1968) believed that post-ischemic "no-reflow" was caused by swelling (edema) of en- dothelial and perivascular glial cells, resulting in a narrowing of the vascular lumen. However, displacing blood from the brain by Ringer's lactate or saline solution before stopping flow (Ames et al., 1968); or marked acute hemodilution with mannitol, glucose, or saline (Fischer and Ames, 1972); or intravascular rinsing of the brain during ischemia with various saline solutions (Olsson and Hossmann, 1971), caused the lesions to vanish. Red cell agglutination or increased viscosity of blood was implicated as a contributing cause, but as heparin had no protective effect there was no evidence of micro-thrombosis.

It has been observed that the amount of demonstrable obstruction is related to the perfusion pressure (Fischer and Ames, 1972; Cantu and Ames, 1969).

In this study we have confirmed our previous observations of partial reversal of the low flow state by injection of epinephrine. Careful measurement of aortic perfusion pressure indicates a marked drop following prolonged ischemia (16 min), presumably due to marked vasodilatation of the peripheral vascular bed secondary to ischemia. This marked decrease in peripheral vascular resistance can be reversed by the vasoconstricting effects of epinephrine which in turn causes an increase in cerebral perfusion pressure.

It is evident that in clinical situations where prolonged ischemia has occurred, e.g. following cardiac arrest, immediate treatment must be concentrated on maintaining an adequate systemic blood pressure in order to reperfuse and resuscitate the brain. Routine injection of epinephrine during cardiac resuscitation is thus strongly supported.

These studies do not answer the questions as to whether cerebrovascular resistance is increased following total cerebral ischemia or whether epinephrine has a direct effect on the cerebral vasculature in this situation.

Our in vitro experiments indicate two cerebral artery populations, "large" and "small" arteries. Previous studies indicated a massive increase in the interstitial and perivascular $\mathrm{K}^{+}$concentration following prolonged cerebral ischemia. On the basis of the in vitro studies this hyperkalemia would produce intense vasoconstriction of the larger cerebral vessels but would dilate the smaller cerebral vessels. The net effect on cerebral blood flow is not certain. The clinical significance of perivascular hyperkalemia, its relationship to $\mathrm{H}^{+}$ion, $\mathrm{CO}_{2}$, anoxia, and pharmacologic agents awaits further clarification.

Inadequate perfusion of the brain during resuscitation from circulatory arrest may inhibit neuronal recovery. Cerebral perfusion is enhanced by epinephrine, largely through its constrictor effect on peripheral vessels resulting in an increase in aortic and cerebral perfusion pressures. We support routine use of epinephrine during cardiac resuscitation to facilitate resuscitation of the brain.

\section{ACKNOWLEDGEMENTS}

This study was supported by grants from the Medical Research Council of Canada and from the Manitoba Heart Foundation.

\section{REFERENCES}

AMES, A., WRIGHT, L. and KOWADA, M. et al. (1968). Cerebral ischemia II. The no-reflow phenomenon. Amer. J. Path. 52, 437-448.

CANTU, R. C., AMES, A., DIGIACINTO, G. and DIXON, J. (1969). Hypotension: A major factor limiting recovery from cerebral ischemia. J. of Surgical Research. 9: 525-529.

CHIANG, J., KOWADA, M. and AMES, A., et al. (1968). Cerebral ischemia III. Vascular changes. Amer J Path. 52: 455-463.

FISCHER, E. G. and AMES, A. (1972). Studies on mechanisms of impairment of cerebral circulation following ischemia: Effect of hemodilution of perfusion pressure. Stroke. 3: 538-542.

FISCHER, E. C. (1973). Impaired perfusion following cerebrovascular stasis. Arch. Neurol. 29: 361-364.

GINSBERG, M. D. and MYERS, R. E. (1972). The topography of impaired microvascular perfusion in the primate brain following total circulatory arrest. Neurology. 22: 998-1011.

HOSSMANN, K. A. and OLSSON, Y (1970). Suppression and recovery of neuronal function in transient cerebral ischemia. Brain Res. 22: 313-325.

HOSSMANN, K. A. and LECHTAPEGRÜTER, H. (1971/72). Blood flow and recovery of the cat brain after complete 
ischemia for 1 hour. European Neurology. 6: $318-322$.

HOSSMANN, V and HOSSMANN, K. A. (1973). Return of neuronal functions after prolonged cardiac arrest. Brain Research. 60:423-437

LITTLE, J R., KERR, F W L. and SUNDT, T. M. (1976). Microcirculatory obstruction in focal cerebral ischemia: An electron microscopic investigation in monkeys. Stroke. 7: 25-29.

MORRIS, M. (1974). Hypoxic and extracellular potassium activity in the guinea-pig cortex. Can. J. Physiol. Pharmacol. 52: 872-882.
OLSSON, Y and HOSSMANN, K. A. (1971). The effect of intravascular saline perfusion on the sequelae of transient cerebral ischemia. Light and electron microscopal observations. Acta. Neuropath. (Berlin). 17: 68-79.

OSBURNE, R. C. and HALSEY, J. H. (1975). Cerebral blood flow. A predictor of recovery from ischemia in the gerbil. Arch. Neurol. 32: 457-461.

SAFAR, P., STEZOSKI, $\mathrm{W}$ and NEMOTO. E. M. (1976). Amelioration of brain damage after 12 mintues cardiac arrest in dogs. Arch. Neurol. 33: 91-95.
WADE, J. G.. AMTORP, O and SORENSEN, S. C. (1975). The "Low-flow" state ing cerebral ischemia. Arch. Neurol. 32: 381-384.

WADE, J. G., TWEED. W A. and DAVIDSON, W J. (1976). The "Low-flow" state following total cerebral ischemia. In Brain Edema: Formation and resolution. Ed. Hanna Pappius. Springer-Verlag (Heidelberg).

YASHON, D., WAGNER, F C. and WHITE, R. J., et al. (1971). Intracranial pressure during circulatory arrest. Brain Res. 31: 139-150. 